\title{
Vibration Analysis of Cracked Composite Laminated Plate: A Review
}

\author{
MUHAMMAD IMRAN*, RAFIULLAH KHAN*, AND SAEED BADSHAH*
}

RECEIVED ON 09.03.2018 ACCEPTED ON 25.05.2018

\begin{abstract}
Composites are one of the rapidly consuming materials due to their utmost attractive applications ranging from the aerospace to the agricultural products. The composite structures usually experience vibration during service. Experiments showed that presence of delamination in composite structures is one of the major causes of failures in laminated structures. Presence of delamination in a structure not only significantly impacts the stiffness of the structure with declining trends but also affect their vibration properties. The purpose of this paper is to review the literature studies on the effect of vibration on composite delaminated structures subjected to different boundary conditions. The literature studies have been classified on the basis of methodology adpated to analyze the problem i.e experimental work, analytical approaches and finite element methods. In this review particular attention has been given to the study of results attained from the analytical analysis, finite element and experimental works. Comparison of the results conducted by other researchers in the field of the free and forced vibration behavior of the composite laminates subjected to delamination or cracked structures has also been studied. Studies have shown that the location and size of delamination in composite structures significantly impacted the natural frequencies and mode shapes.
\end{abstract}

Key Words: Vibration Testing,Delamination, Composite Structure, Cracked Composite,Finite Element Analysis, Analytical Technique.

\section{INTRODUCTION}

$\mathrm{F}$ iber-reinforced composites have gained wide use in many aspects of engineering applications [1]. For example, they have been applied in ship building, mechanical, aerospace, etc. They are preferred because of the advantages they have such as superior mechanical characteristics, high-strength, their stiffness ratio to weight is excellent [2].

The characteristics of the CFRP (Carbon-Fiber-Reinforced Polymers)formed depend on the Reinforcement and the particular matrix used. The reinforcement components like elasticity and stress determines the rigidity and strength of the CFRP. This is why the property strength of CFRP is usually described as directional and distinct from isotropic structures like aluminum. It must not be forgotten that the carbon-fiber layout also has the ability to influence the CFRP properties. Laminates are formed by stacking different laminates (usually two or more) with different or similar fiber orientation under global direction [3]. Different or similar composite materials with varying thicknesses

Authors E-Mail: (muhammad.imran@iiu.edu.pk, rafiullah.khan@iiu.edu.pk, saeed.badshah@iiu.edu.pk)

* Department of Mechanical Engineering, International Islamic University, Islamabad. 
can be used to form the laminate under any stacking sequence. Stacking sequence optimization of composite laminates requires the use of least amount of layers, highest fiber quality and highest possible thickness for each of the layers [4].

The composite structures usually experience vibration during service. The consequences of vibration have a wide impact range from minor issue, such as development of noise in an automobile component, to significant damage occurrences to the structure or its parts [5-7].

Presence of delamination in a structure affects the stiffness of the composite structure and also vibration properties. Delamination length and size decrease the natural frequencies and therefore to find effect of delamination on vibration characteristics is quite important for highly sensitive applications [8-9]. Experiments proved that in the presence of delamination, mode shapes of the composite materials were changed [10]. A Comprehensive review study of vibration analysis of cracked composite laminated is lacking. The objective of this paper is to present a comprehensive review of the state of the art studies on the vibration analysis of cracked composite plate.

\section{VIBRATION OF COMPOSITE WITH CRACK OR DELAMINATION}

The literature studies has been classified according to the techniques i.e. analytical, experimental and finite element analysis. The next sections critically describe the prominent studies according to the above theme.

\subsection{Analytical Techniques}

Dey et. al. [11] conducted vibration analysis on the graphite-epoxy composite shells using Lagrange's equation of motion. On an increase in twist angle of fiber orientation, its frequency values tend to decrease. The fundamental frequencies increase for twisted shells proportional to the delamination towards free end subjected to the stationary condition. However, values of fundamental frequencies of stationary twisted shells depends upon the delamination location and its value decreases as the location of delamination is near free end. When a delamination is incorporated at the mid plane as shown in Fig. 1, NDFF (Non-Dimensional Fundamental Frequencies) have minimal values and second natural frequencies are attained.

NDFF decreases as the twist angle from $0-45^{\circ}$ is increased. Irrespective of twist angle, on the changes in the location of delamination as shown in Fig. 2, it affects the NDFF values and NDFF value gradually decreases to minimal if it is located at the vertical mid-plane and its value at the bottom surface gradually increases with location.

Marjanovic and Vuksanovi [12] did an investigation to find the mode shapes, fundamental frequencies and critical buckling loads. They developed the numerical model for the delaminated sandwich composite plate. However, for free cantilevered plate, shear deformation does not affect the natural frequencies however shear deformation has considerable effect on the simply supported or clamped plate. Since the amplitude is small, larger value of frequency would be observed with greater length of delamination. Frequency increases relatively slow with an increase in length of the delamination. As the value of amplitude is increased, the influence of the positions or locations of delamination gets clearer. The influence by transverse shear deformation has significant importance and cannot be considered as no impact for non-linear vibration characteristics of composite beam. 
Chen [13] did an investigation to find the effect of circular delamination on circular composite laminated plate. It was analyzed that the radius and depth of delamination has a considerable effect on the vibration characteristics of delaminated composite plate. Boundary conditions were formulated using ReissnerVariational Principle. First order shear deformation was used for formulation of governing equation. It was concluded that an increase in delamination radius rapidly decreased the value of natural frequency of the composite laminated plate as shown in Table1. However, the value of natural frequency of laminated circular composite plate decreased with decrease in the delamination depth. Whatever the delamination depth is, delamination length affects the natural frequencies. Natural frequencies are impacted by both the delamination depths and delamination radius.

Lee [14] conducted free vibration analysis using layerwise theory approach to find the vibration properties of delaminated composite beam. Hamilton's principle was used to determine the equations of motion and the analytical results were compared with Wang [15]. Both the theories predicted that frequency values decreased as the delamination length increased as shown in Table2.

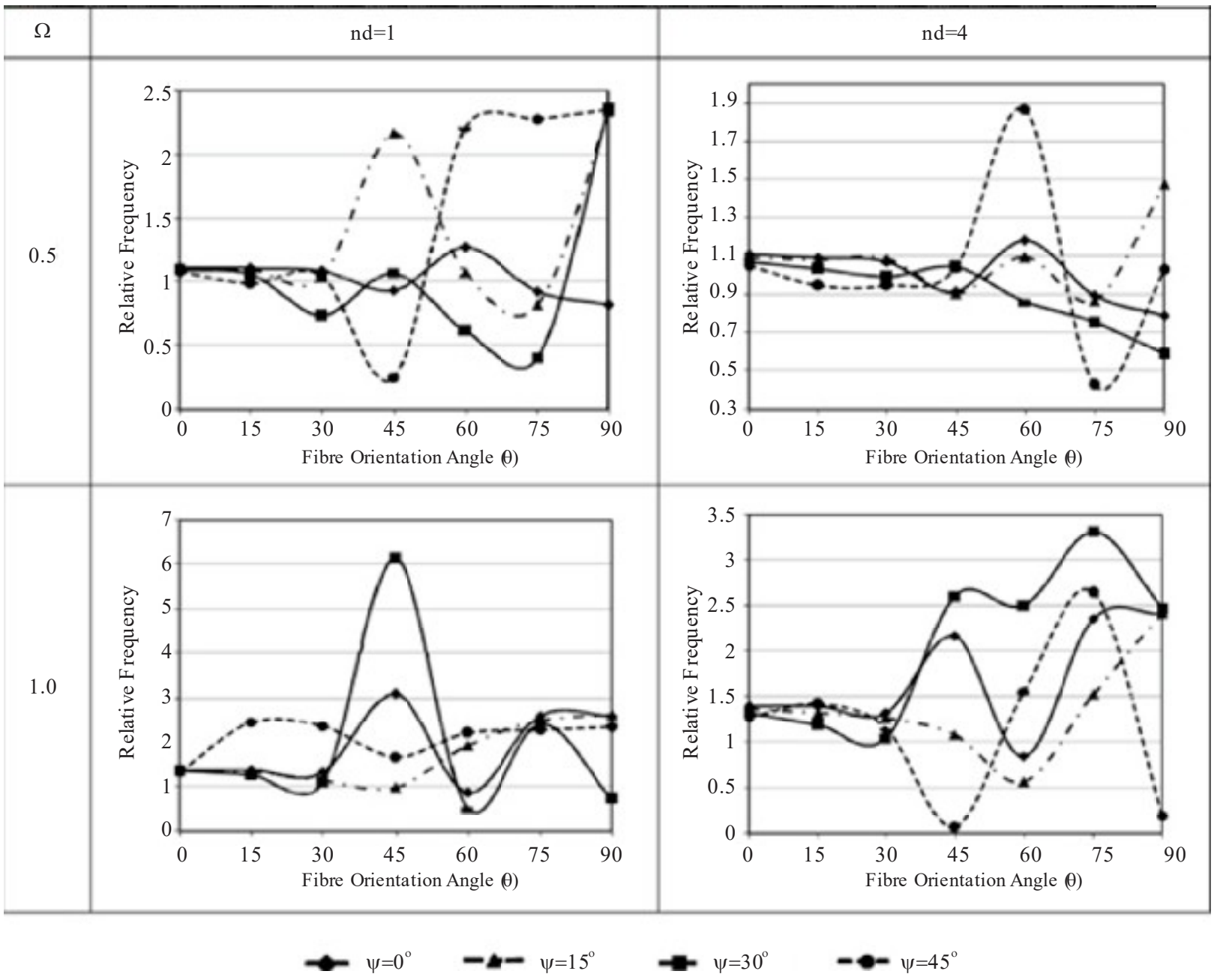

FIG. 1. VARIATION OF RELATIVE NON-DIMENSIONAL FUNDAMENTAL FREQUENCIES OF GRAPHITE-EPOXY ANGLE-PLY COMPOSITE CONICAL SHELLS [11]

Mehran University Research Journal of Engineering \& Technology, Volume 38, No. 3, July, 2019 [p-ISSN: 0254-7821, e-ISSN: 2413-7219] 
Hirwani et. al. [16] did an investigation to analyze the effect of presence of delamination on the vibration characteristics of spherical structure, cylindrical structure, elliptical structure, hyperboloid structure and flat structures of laminated curved composites. Higher order shear deformation theory HSDF (Health Strategy and Delivery Foundation) was taken to develop the model. The frequency responses were obtained using ANSYS and mode shapes were obtained using MATLAB. The experimental, analytical and ANSYS results were compared

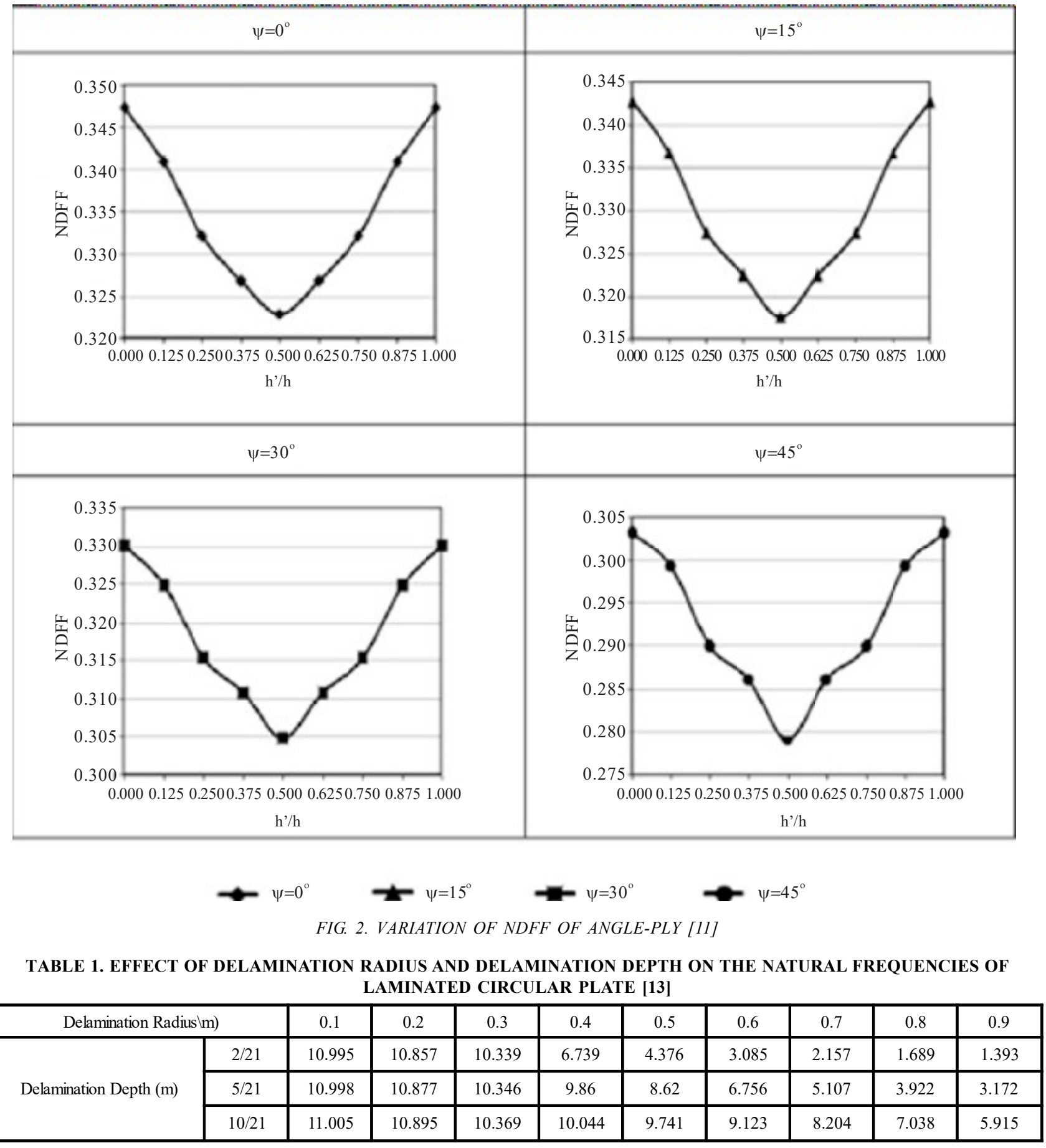

Mehran University Research Journal of Engineering \& Technology, Volume 38, No. 3, July, 2019 [p-ISSN: 0254-7821, e-ISSN: 2413-7219] 
for delamination area of $6.25,11.11,25$ and $56.25 \%$ of the total area. Result of first six mode shapes are evaluated. It was concluded that the results obtained from analytical method are in close agreement to the experimental results as shown in Table 3. Composite structures with different shapes have different vibration response in the presence of delamination. However, the natural frequencies have not much influenced by the size of delamination on lower modes i.e. natural frequencies for $0 \%$ delamination have almost similar response to $6.25 \%$ delamination for first mode number. However, second modes, the difference between the two increased. Also the experimental values are less as compared to analytical models and ANSYS. This can be due to the techniques adapted in experimental work.

Nanda et. al. [17] find the vibration response of delaminated composite shell using first order shear deformation theory subjected to cylindrical, spherical and hyperboloid shells. The value of linear frequency showed increasing trend with reduction of number of layers. This frequency difference continues to increase after the six number of layers. Moreover, higher modes were more influenced by the delamination.
Eight-node rectangular thin element was used for Finite element formulation. It was concluded that local internal delamination had slight or negligible influence on the natural frequencies of laminated composite plate with multi-layers. Moreover, it was also found that natural frequency decreases if the area of delamination is increased. On the other hand, natural frequency increases if the mode numbers increased.

Mujumdar and Suryanarayan [18] did an investigation on the delaminated composite beam by numerical solution using Euler beam theory. Size, boundary conditions, modes and location of delamination largely influence the frequencies. Delamination with shorter length have little impact on fundamental and second mode frequencies subjected to all boundary conditions. However, delamination with larger length have huge impact on fundamental and second mode frequencies subjected to boundary conditions. There is large difference in second mode if compared experimental results.

Szekrényes [19] conducted vibration analysis on delaminated composite beam. Jafari et. al. [20] carried out analytical and finite element analysis on the composite

TABLE 2. NATURAL FREQUENCIES OF A BEAM WITH MIDPLANE DELAMINATION [15]

\begin{tabular}{|c|c|c|c|c|c|c|}
\hline \multirow{2}{*}{ a/l } & \multicolumn{3}{|c|}{ Wang et. al. [15] } & \multicolumn{3}{c|}{ Present [14] } \\
\cline { 2 - 7 } & 1 st & 2nd & 3rd & 1st & 2nd & 3rd \\
\hline 0 & 22.39 & 61.67 & 120.91 & 22.36 & 61.61 & 120.68 \\
\hline 0.1 & 22.37 & 60.76 & 120.81 & 22.36 & 60.74 & 120.62 \\
\hline 0.2 & 22.35 & 55.97 & 118.76 & 22.35 & 55.95 & 118.69 \\
\hline 0.3 & 22.23 & 49 & 109.04 & 22.23 & 48.97 & 109.03 \\
\hline 0.4 & 21.83 & 43.87 & 93.57 & 21.82 & 43.86 & 93.51 \\
\hline 0.5 & 20.88 & 41.45 & 82.29 & 20.88 & 41.5 & 82.23 \\
\hline 0.6 & 19.29 & 40.93 & 77.64 & 19.28 & 41.01 & 77.64 \\
\hline 0.7 & 17.23 & 40.72 & 77.05 & 17.22 & 40.8 & 77.12 \\
\hline 0.8 & 15.05 & 39.01 & 75.33 & 15.05 & 39.04 & 75.39 \\
\hline 0.9 & 13 & 35.38 & 69.17 & 12.99 & 35.38 & 69.16 \\
\hline
\end{tabular}

Mehran University Research Journal of Engineering \& Technology, Volume 38, No. 3, July, 2019 [p-ISSN: 0254-7821, e-ISSN: 2413-7219] 
curved beams with single delamination. Hamilton's principle was used for through the width delamination. They find the effect of delamination location and size, stacking sequences, boundary conditions and material anisotropic properties on the natural frequencies of delaminated composite beam.
Joshi et. al. [21] conducted vibration analysis for cracked orthotropic rectangular composite plate. Analytical model was based on classical plate theory. They found that vibration properties were affected by the crack length. It was concluded that crack across the fibers more affected the frequencies.

TABLE 3. EFFECT OF DELAMINATION SIZE ON THE FIRST SIX MODES FOR EXPERIMENTAL, ANALYTICAL AND ANSYS METHODS [16]

\begin{tabular}{|c|c|c|c|c|c|}
\hline $\begin{array}{c}\text { Size of Delamination } \\
\text { (\% of Total Area) }\end{array}$ & Mode Number & Experimental & Model-1 & Model-2 & ANSYS \\
\hline \multirow{6}{*}{0} & 1 & 21 & 23.68 & 24.05 & 23.878 \\
\hline & 2 & 61 & 64.31 & 64.35 & 63.861 \\
\hline & 3 & 140 & 152.06 & 151.89 & 151.16 \\
\hline & 4 & 193.5 & 192.36 & 193.85 & 192.44 \\
\hline & 5 & 228 & 230.28 & 229.85 & 228.93 \\
\hline & 6 & 399 & 404.51 & 403.25 & 403.5 \\
\hline \multirow{6}{*}{6.25} & 1 & 20.4 & 23.4 & 23.82 & 23.73 \\
\hline & 2 & 55.5 & 61.67 & 62.037 & 63.145 \\
\hline & 3 & 142 & 145.68 & 14.86 & 149.16 \\
\hline & 4 & 185.5 & 187.79 & 190.24 & 190.36 \\
\hline & 5 & 221 & 225.46 & 227.76 & 225.36 \\
\hline & 6 & 394 & 399.31 & 402.32 & 394.46 \\
\hline \multirow{6}{*}{11.11} & 1 & 20.1 & 23.22 & 23.64 & 23.71 \\
\hline & 2 & 59 & 60.2 & 60.59 & 63.615 \\
\hline & 3 & 140 & 145.67 & 147.8 & 149.25 \\
\hline & 4 & 183 & 186.76 & 189.08 & 190.11 \\
\hline & 5 & 222 & 226.09 & 228.44 & 227.54 \\
\hline & 6 & 397 & 403.9 & 406.66 & 397.04 \\
\hline \multirow{6}{*}{25} & 1 & 20 & 22.09 & 22.47 & 23.69 \\
\hline & 2 & 48.5 & 54.91 & 55.34 & 63.451 \\
\hline & 3 & 135 & 137.44 & 139.44 & 148.48 \\
\hline & 4 & 182 & 175.51 & 177.5 & 190.53 \\
\hline & 5 & 201.5 & 211.69 & 214.03 & 224.9 \\
\hline & 6 & 380 & 371.3 & 375.48 & 394.64 \\
\hline \multirow{6}{*}{56.25} & 1 & 19.4 & 18.94 & 19.26 & 23.628 \\
\hline & 2 & 41.2 & 46.2 & 46.58 & 63.594 \\
\hline & 3 & 112 & 117.78 & 119.55 & 147.46 \\
\hline & 4 & 137 & 141.93 & 143.58 & 189.44 \\
\hline & 5 & 184 & 181.735 & 184.01 & 224.44 \\
\hline & 6 & 276 & 284.0583 & 288.33 & 392.64 \\
\hline
\end{tabular}


Torabi et. al. [22] conducted experiments to find the effect of delamination on delaminated cross ply composite beams and concluded that lowest frequency was observed in lowest mode. Constraint models showed greater natural frequency values than the free-constraint models.

Manda et. al. [23] carried out experiments to find the vibration characteristics of glass fiber reinforced polymer skew plates with cut-outs. Talookolaei et. al. [24] did an investigation on Composite beam with single delamination using Hamilton's principle. They concluded that an increase in delamination length significantly reduced the natural frequencies. Natural frequencies increased with an increase in the rotating speed.

\subsection{Experimental Techniques}

Hammami et. al. [25] conducted experiments to find the linear and nonlinear vibration characteristics of composite structures with delamination. Interlaminated delaminated GFRP (Glass Fiber Reinforced Plastic) was used. Specimens were developed using hand lay-up method and were analyzed using resonance method. Natural frequencies decreased with delamination lengths. Increase in nonlinearity in composite was observed on delamination length. Linear parameters are not much sensitive to the parameter of delamination than nonlinear parameters.

Hirwani et. al. [26] conducted experiments on woven glass epoxy and found the delamination effect on the vibration behavior of woven glass/epoxy composite plate. Numerical results were compared with ANSYS results along with experimental results. The governing equation was derived using Hamilton's principle. Model was developed by using Teflon of $6.25 \%$ as delamination of total laminate area. It was concluded that natural frequency decreased upon an increase in the thickness ratio as shown in Fig. 3.

Mohanty et. al. [27] investigated free vibrations of woven fiber glass/epoxy composite plate with delamination. They used first order shear deformation theory as governing equation to develop an eight-noded 2D (TwoDimensional quadratic ISO-parametric element. Mid plane square sized delamination was incorporated at 6.25, 25 and $56.25 \%$ of the composite plate area and was

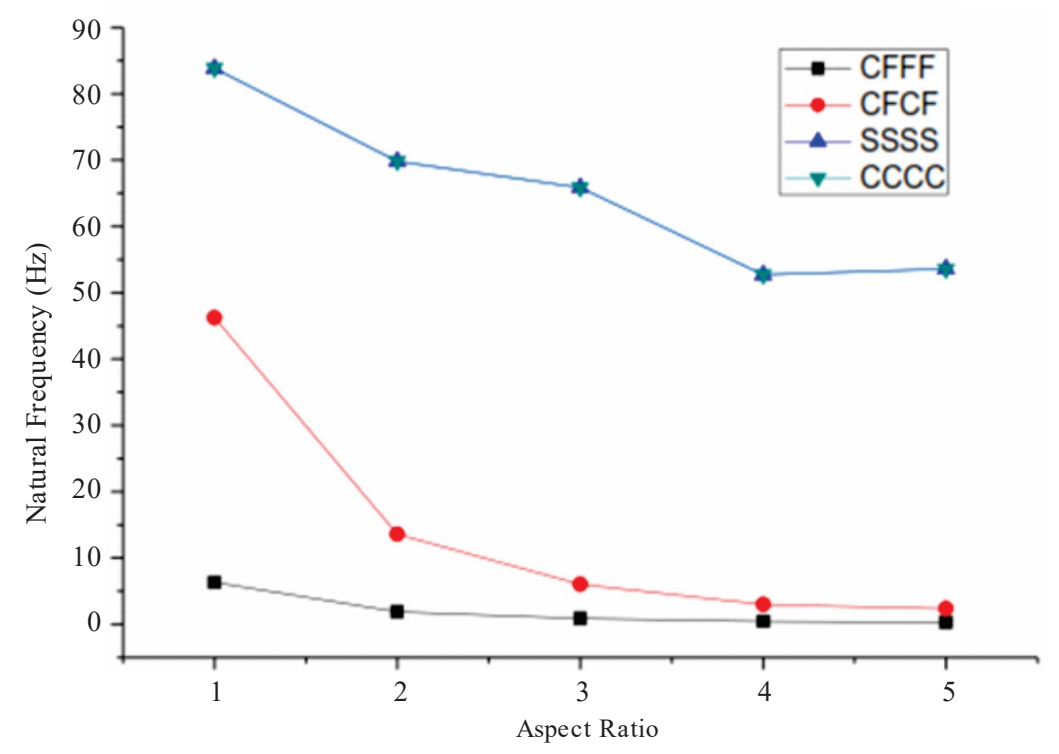

FIG. 3. NATURAL FREQUENCY WITH CENTRAL DELAMINATION FOR VARYING SUPPORT CONDITIONS [26]

Mehran University Research Journal of Engineering \& Technology, Volume 38, No. 3, July, 2019 [p-ISSN: 0254-7821, e-ISSN: 2413-7219] 
concluded that presence of delamination reduced the natural frequencies by 10,14 and $22 \%$ as compared with the natural frequencies without delamination. For large delamination area of $56.25 \%$, natural frequency was less impacted subjected to cantilever boundary conditions. An increase in the aspect ratio by 1:0 also increases the natural frequency. But the fundamental natural frequencies increased two times and four times with aspect ratio of 1.5 and 2.0 respectively. These results were compared with analytical solution and found good agreement. Experimental work was performed by semiautoclave and analytical results were generated using classical laminated beam theory. On the increase of delamination length, natural frequencies proportionally decreased. Minimum value of natural frequency was observed as the delamination level reaches to 0.5 subjected to all cross-ply and angle-ply laminations. The value of natural frequency decreased with an increase in the number of delamination. This behavior was also reported by Nguyen et. al. [28]. Ju et. al. [29] did an investigation on the delaminated composite plate using Finite Element method with 8-node, 40 degree of freedom ISO-parametric plate element and mindlin theory was used for analytical solution. They concluded that more the constrained, greater the effect of delamination size observed. Higher mode shapes were badly affected by delamination size.

Hammai et. al. [30] found the relation of nonlinearity with delamination. Delaminated glass fiber reinforced composite was used. Handy layup method was used for laminates and central delamination was intruded for experimental setup. It was concluded that Nonlinearity of composite structure increases as the delamination increases.

Bangade et. al.[10] carried out experimental and numerical analysis to find the effect of delamination on the natural frequencies of composite beam.

\subsection{Finite Element Method}

Gowda et. al. [31] carried out finite element analysis to analyze the effect of delamination location and delamination size on the natural frequencies of delaminated composite beams. They used ANSYS software package to find the mode shapes and frequencies. It was concluded that natural frequencies decreased with increase in delamination size for CFFF and SSSS boundary constraints.

Rout et. al. [32] conducted finite element analysis to find the impact of delamination, fiber orientation and twist angle on the vibration characteristics of pre-twisted laminated cylindrical shells. They used Lagrange's equation of motion. It was concluded that fundamental frequencies increased significantly by addition of stiffeners. NDFF significantly increased from 0-90 degree but rapidly decreased between 30-60 degrees irrespective of the delamination.

Sahoo et. al. [33] conducted finite element method analysis using MATLAB code to find the delamination influence on the non-linear characteristics of composite laminated plate. They used higher order shear deformation theory as governing equations. It was concluded that structural stiffness decreases with an increase in the size of delamination.

Ramazan et. al. [20] did an investigation to find the effect of delamination size and location on the free vibration characteristics of delaminated curved beams. The governing equations were produced using Hamilton's principle. Three interfaces were developed to consider corresponding effects as shown in Fig. 4.

Ganesh et. al. [34] conducted vibration analysis using first order shear deformation theory and computational methods to analyze vibration characteristics of delaminated composite plate.

Mehran University Research Journal of Engineering \& Technology, Volume 38, No. 3, July, 2019 [p-ISSN: 0254-7821, e-ISSN: 2413-7219] 
It was concluded that simple supported constrained mode (SSSS) showed greater natural frequencies than cantilever-free boundary conditions (CFFF). Also natural frequency with delamination at mid-plane is higher than the natural frequency values obtained at other interfaces.

Shankar et. al. [35] developed MATLAB code to find the vibration properties of delaminated composite plate. First order shear deformation theory was used for analytical results. $56.25,25$ and $6.25 \%$ of the total plate area was considered as delamination area. Erdelyi and Hashemi [36] carried out finite element free vibration analysis of a delaminated layered composite beam. Singh et. al. [37] used finite element non-linear models to detect the delamination in composite structures.Shankar et. al. [38] conducted vibration analysis to find the effect of crack length on natural frequencies of Graphite Epoxy Composite pre twisted shells using Finite element method. Governing equations were generated by using the minimum potential energy approach. It was concluded that delamination caused the natural frequencies to decrease. Rout et. al. [39] carried out finite element analysis using first order shear deformation theory for the composite delaminated shallow cylindrical shells. They studied the influence of delamination location, number of layers, rotational speed and twist angle on the free vibration response of the delaminated composite shells.

\section{DISCUSSIONS}

In this section, behavior of composite structures in presence of delamination is discussed. After detailed study on the analytical, experimental and finite element work carried out to find the influence of delamination in composite structures, following observations has been made.

On increase in depth of crack increased the fundamental frequencies. Also for a fixed crack depth, the value of fundamental frequency also decreased if the location of the crack got nearer to the center of the beam. Primary and secondary frequencies decrease as the length of the delamination increased however reduction of primary frequency is not significant. It was also observed that natural frequency and mode shapes are largely dependent of the assumed constraints. It was concluded that double delamination further reduced the value of natural frequency and mode shape of the beam. When the delamination size is small, insignificant changes in natural frequency are observed. It was shown that effect of multi delamination are more significant than those for single delamination.

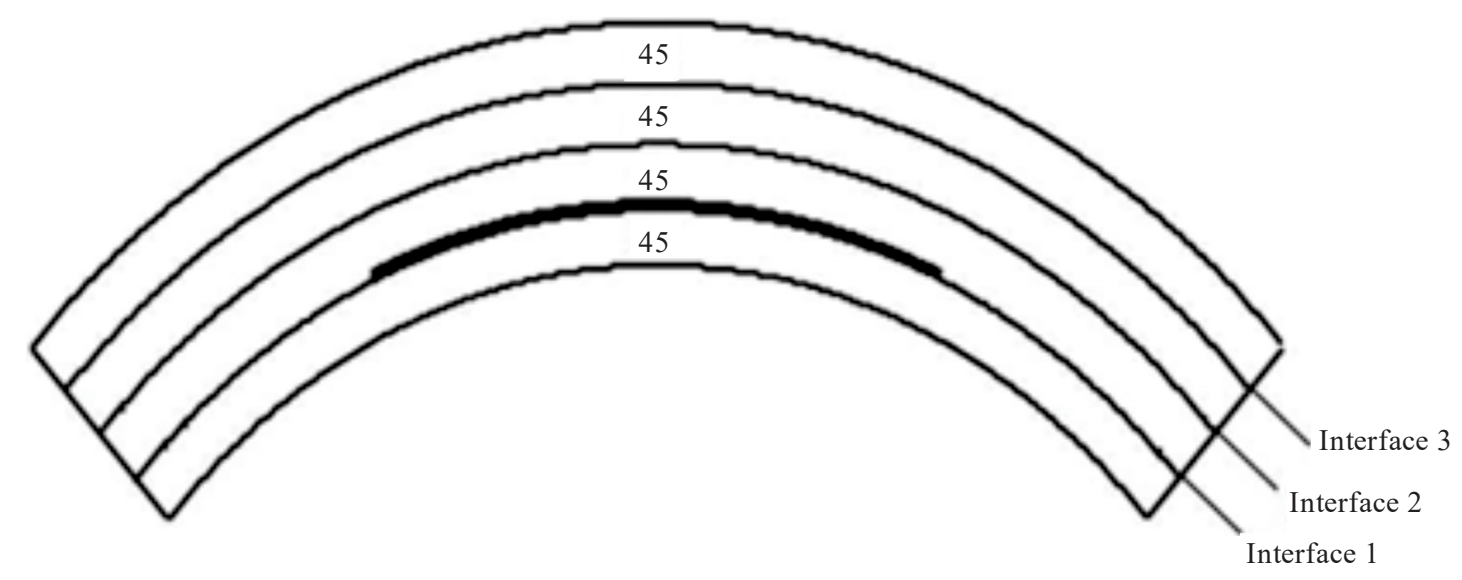

FIG. 4. INTERFACES LOCATION OF CENTRAL DELAMINATION[20] 
Amazingly, for constrained mode shape model, declining trends in frequencies have been observed. When a delamination is incorporated at the mid plane, minimum value of non-dimensional fundamental frequencies is obtained. For small amplitude, larger values of frequency would be observed with greater length of delamination.

On the other hand, we have also seen that the natural frequencies of laminated circular plates decreased with decrease in the delamination depth. For plates without delamination, natural frequency increases with increase in mode number. It is important to note that the frequencies decrease with increase in delamination length and width but the frequencies decrease with increase in depth of crack.

Interestingly, delamination size equivalent to one fourth of the total length of structures, has no significant impact on the fundamental and higher frequency modes subjected to all boundary conditions. It clearly shows that shorter crack is ignorable for ordinary structures.

Delamination lengths along with diameter alone also impacts non-linearity behavior in composite plate. Also increase in the bending stiffness caused an increase in the frequency. Natural frequency decreased as the thickness ratio increased and natural frequencies increased with an increase in constrained modes.

By the above discussion, it is important that delamination lengths, widths and depths have different impacts on the natural frequencies and mode shapes of the composite structures.

\section{CONCLUSION}

Cracks or delamination in composite plates are inevitable during service period. There can be different parameters that effect its performance like service conditions like variations in temperature or pressure. It has been experimentally validated that any specific delamination in a structure affects the dynamic performance of the whole structure. Moreover, resonance or crack propagation within surface induce huge displacements or dislocations that ultimately leads to the failure of the structure. Because of their application significance, unique properties and widespread usage, the linear or non-linear criterion of these cracked/delaminated structures is to be investigated with of great interest. Earlier, various numerical techniques were taken into consideration for predicting the behavior of vibrations in composite plates.

However, the vibration behavior in the presence of delamination or cracks in composite laminates is least investigated. The vibration can cause the cracks or delamination to grow to critical sizes and leads to structural failure. The existing models of vibration crack growth are not appropriately based on the physics of the dynamic behavior of cracked bodies. Moreover, the existing numerical and FEA investigation have not been validated using experimentation in case of carbon fiber reinforced polymer composite structures. This is causing a huge research gap in the complete characterization of dynamic behavior of composites in the presence of cracks or delamination.

\section{ACKNOWLEDGMENT}

Author acknowledges the support and is thankful to the Chairman, Department of Mechanical Engineering, International Islamic University, Islamabad, Pakistan.

\section{REFERENCES}

[1] Hensher, D.A., "Fiber-Reinforced-Plastic (FRP) Reinforcement for Concrete Structures: Properties and Applications", Elsevier, 2016.

[2] Agarwal, B.D., Broutman, L.J., and Chandrashekhara, K., "Analysis and Performance of Fiber Composites", John Wiley \& Sons, 2017. 
[3] Shirvanimoghaddam, K., Hamim, S.U., Akbari, M.K., Fakhrhoseini, S.M., Khayyam, H., Pakseresht, A.H., Ghasali, E., Zabet, M., Munir, K.S., and Jia, S., "Carbon Fiber Reinforced Metal Matrix Composites: Fabrication Processes and Properties", Composites Part-A: Applied Science and Manufacturing, Volume 92, pp. 70-96, 2017.

[4] Rajesh, M., Singh, S.P., and Pitchaimani, J., "Mechanical Behavior of Woven Natural Fiber Fabric Composites: Effect of Weaving Architecture, Intra-Ply Hybridization and Stacking Sequence of Fabrics", Journal of Industrial Textiles, Volume 47, No. 5, pp. 938-959, 2018.

Cavallo, T., Zappino, E., and Carrera, E., "Free-Vibration Analysis of Space Vehicle Structures Made by Composite Materials", Composite Structures, Volume 183, 2017.

Sajid, R.Z.A., "Buckling Analysis of an Ocean Current Turbine Blade", International Journal of Science, Engineering and Innovative Research, Volume 2, pp. 6-11, 2015.

de Luzuriaga, A.R., Martin, R., Markaide, N., Rekondo, A., Cabañero, G., Rodríguez, J., and Odriozola, I., "Epoxy Resin with Exchangeable Disulfide Crosslinks to Obtain Reprocessable, Repairable and Recyclable FiberReinforced Thermoset Composites", Materials Horizons, Volume 3, No. 3, pp. 241-247, 2016.

[8] Brunner, A., Stelzer, S., Pinter, G., and Terrasi, G., "Cyclic Fatigue Delamination of Carbon Fiber-Reinforced Polymer-Matrix Composites: Data Analysis and Design Considerations", International Journal of Fatigue, Volume 83, pp. 293-299, 2016.

[9] Zhou, H., Du, X., Liu, H.-Y., Zhou, H., Zhang, Y., and Mai, Y.-W., "Delamination Toughening of Carbon Fiber/ Epoxy Laminates by Hierarchical Carbon NanotubeShort Carbon Fiber Interleaves", Composites Science and Technology, Volume 140, pp. 46-53, 2017.

[10] Bangade, M.Y., and Kulkarni, V., "Experimental \& Numerical Analysis of Composites with Delaminations", Volume 4, 2017.

[11] Dey, S., and Karmakar, A., "Free Vibration Analyses of Multiple Delaminated Angle-Ply Composite Conical Shells - A Finite Element Approach", Composite Structures, Volume 94, No. 7, pp. 2188-2196, 2012.
[12] Marjanoviæ, M., and Vuksanoviæ, D., "Layerwise Solution of Free Vibrations and Buckling of Laminated Composite and Sandwich Plates with Embedded Delaminations", Composite Structures, Volume 108, pp. 9-20, 2014.

[13] Chen, D.-L., "Dynamic Analysis of Composite Laminated Circular Plate with Circular Delamination", Journal of Mechanics, Volume 32, No. 6, pp. 683-692, 2016.

[14] Lee, J., "Free Vibration Analysis of Delaminated Composite Beams", Computers \& Structures, Volume 74, No. 2, pp. 121-129, 2000.

[15] Wang, J., Liu, Y., and Gibby, J., "Vibrations of Split Beams", Journal of Sound and Vibration, Volume 84, No. 4, pp. 491-502, 1982.

[16] Hirwani, C.K., Patil, R.K., Panda, S.K., Mahapatra, S.S., Mandal, S.K., Srivastava, L., and Buragohain, M.K., "Experimental and Numerical Analysis of Free Vibration of Delaminated Curved Panel", Aerospace Science and Technology, Volume 54, pp. 353-370, 2016.

[17] Nanda, N., and Sahu, S.K., "Free Vibration Analysis of Delaminated Composite Shells Using Different Shell Theories", International Journal of Pressure Vessels and Piping, Volume 98, pp. 111-118, 2012.

[18] Mujumdar, P.M., and Suryanarayan, S., "Flexural Vibrations of Beams with Delaminations", Journal of Sound and Vibration, Volume 125, No. 3, pp. 441-461, 1988.

[19] Szekrényes, A., "Vibration and Parametric Instability Analysis of Delaminated Composite Beams", World Academy of Science, Engineering and Technology, International Journal of Chemical, Molecular, Nuclear, Materials and Metallurgical Engineering, Volume 10, No. 7, pp. 821-828, 2016.

[20] Jafari-Talookolaei, R.-A., Abedi, M., and Hajianmaleki, M., "Vibration Characteristics of Generally Laminated Composite Curved Beams with Single Through-theWidth Delamination", Composite Structures, Volume 138, pp. 172-183, 2016.

[21] Joshi, P.V., Jain, N.K., and Ramtekkar, G.D., "Analytical Modelling for Vibration Analysis of Partially Cracked Orthotropic Rectangular Plates", European Journal of Mechanics - ASolids, Volume 50, pp. 100-111, 2015. 
[22] Torabi, K., Shariati-Nia, M., and Heidari-Rarani, M., "Experimental and Theoretical Investigation on Transverse Vibration of Delaminated Cross-Ply Composite Beams", International Journal of Mechanical Sciences, Volume 115-116, pp. 1-11, 2016.

[23] Mandal, A., Ray, C., and Haldar, S., "Free Vibration Analysis of Laminated Composite Skew Plates with CutOut", Archive of Applied Mechanics, Volume 87, No. 9, pp. 1511-1523, 2017.

[24] Jafari-Talookolaei, R.-A., "Analytical Solution for the Free Vibration Characteristics of the Rotating Composite Beams with a Delamination", Aerospace Science and Technology, Volume 45, pp. 346-358, 2015.

Hammami, M., El-Mahi, A., Karra, C., and Haddar, M., "Experimental Analysis of the Linear and Nonlinear Behaviour of Composites with Delaminations", Applied Acoustics, Volume 108, pp. 31-39, 2016.

[26] Hirwani, C., Sahoo, S., and Panda, S.,"Effect of Delamination on Vibration Behaviour of Woven Glass/ Epoxy Composite Plate-An Experimental Study", Conference Series: Materials Science and Engineering, Volume 115, No. 1, IOP Publishing, 2016.

[27] Mohanty, J., Sahu, S., and Parhi, P., "Numerical and Experimental Study on Free Vibration of Delaminated Woven Fiber Glass/Epoxy Composite Plates", International Journal of Structural Stability and Dynamics, Volume 12, No. 2, pp. 377-394, 2012.

[28] Nguyen-Minh, N., Tran-Van, N., Bui-Xuan, T., and Nguyen-Thoi, T., "Free Vibration Analysis of Corrugated Panels Using Homogenization Methods and a Cell-Based Smoothed Mindlin Plate Element (CS-MIN3)", ThinWalled Structures, Volume 124, pp. 184-201, 2018.

[29] Ju, F., Lee, H., and Lee, K., "Finite Element Analysis of Free Vibration of Delaminated Composite Plates", Composites Engineering, Volume 5, No. 2, pp. 195-209, 1995.

[30] Hammami, M., El-Mahi, A., Karra, C., and Haddar, M., "Nonlinear Behaviour of Glass Fibre Reinforced Composites with Delamination”, Composites Part-B: Engineering, Volume 92, pp. 350-359, 2016.
[31] Gowda, C.V., Rajanna, N., and Udupa, N., "Investigating the Effects of Delamination Location and Size on the Vibration Behaviour of Laminated Composite Beams", Materials Today: Proceedings, Volume 4, No. 10, pp. 10944-10951, 2017.

[32] Rout, M., Hota, S.S., and Karmakar, A., "Free Vibration Characteristics of Delaminated Composite Pretwisted Stiffened Cylindrical Shell", Proceedings of the Institution of Mechanical Engineers, Part-C: Journal of Mechanical Engineering Science, 2017.

[33] Sahoo, S.S., Panda, S.K., and Sen, D., "Effect of Delamination on Static and Dynamic Behavior of Laminated Composite Plate", AIAA Journal, pp. 2530-2544, 2016.

[34] Ganesh, S., Kumar, K.S., and Mahato, P.K., "Free Vibration Analysis of Delaminated Composite Plates Using Finite Element Method", Procedia Engineering, Volume 144, pp. 1067-1075, 2016.

[35] Shankar, G., Keshava Kumar, S., and Mahato, P.K., "Vibration Analysis and Control of Smart Composite Plates with Delamination and Under Hygrothermal Environment", Thin-Walled Structures, Volume 116, pp. 53-68, 2017.

[36] Erdelyi, N.H., and Hashemi, S.M., "On the Finite Element Free Vibration Analysis of Delaminated Layered Beams: A New Assembly Technique", Shock and Vibration, 2016

[37] Singh, A.K., Chen, B.-Y., Tan, V.B., Tay, T.-E., and Lee, H.-P., "Finite Element Modeling of Nonlinear Acoustics/ Ultrasonics for the Detection of Closed Delaminations in Composites", Ultrasonics, Volume 74, pp. 89-98, 2017.

[38] Shankar, G., and Mahato, P., "Vibration Analysis and Control of Delaminated and/or Damaged Composite Plate Structures Using Finite Element Analysis", Materials at High Temperatures, Volume 34, No. 5-6, pp. 342-349, 2017.

[39] Rout, M., Bandyopadhyay, T., and Karmakar, A., "Free Vibration Analysis of Pretwisted Delaminated Composite Stiffened Shallow Shells: A Finite Element Approach", Journal of Reinforced Plastics and Composites, Volume 36, No. 8, pp. 619-636, 2017. 